\title{
Playing With/In Plurality
}

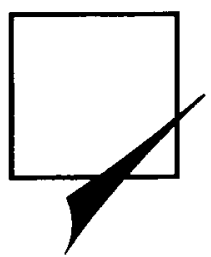

\section{Revitalizing Realities and Relationships in Rotterdam}

\author{
TINEKE A. ABMA \\ Erasmus University, Rotterdam
}

We are living in a postmodern society characterized by a permanent and irreducible plurality. This has serious implications for the practices of social planning and evaluation. This has not always been fully recognized. The dominant discourse in evaluation is modernist in its ambition to rationalize society by the instrumental use of objective, scientific knowledge. This coincides well with centralized, top-down social planning based on analysis and instruction by experts. Although dominant approaches have been criticized for their technocratic orientation, proposed alternatives are incompatible with a decentralized, bottom-up and interactive planning that takes a diversity of perspectives into account. The case of social revitalization in Rotterdam illustrates that a responsive evaluation approach can succesfully support attempts of entrepreneurial, local governments that invite and involve public, private and voluntary stakeholders to revitalize their realities and relationships.

\section{Introduction}

Without universal standards, the problem of the postmodern world is not how to globalize superior culture, but how to secure communication and mutual understanding between cultures. (Bauman, 1992: 102)

Our contemporary society differs remarkably from the industrial society of the 1950s. The social and economic structures reproduced since the industrial revolution have been fragmented into a diversity of networks. New styles of communication and institutionalization are developing. Computer-aided customization-based on flexible, skilled and self-managing teams - undermines the ideas of Fordist mass production with its concepts of pyramidic control designed in classically bureaucratic fashion. Today, opera stars top the Hit Parade and, as a result, the distinction between high and low culture in music gradually becomes less distinct. In street art, happenings, and body art, active participation is substituted for contemplation. The ornamentation, color, and eclecticism of postmodern buildings flout the order prescribed in the canons of functionalism. As low and high technologies expand we become more and more immersed in the social world, and increasingly exposed to the opinions, values, and life-styles of others. The coherent self comes to resemble a pastiche, an imitatively assembled construct. Under 


\section{Tineke A. Abma}

the domination of the media individual lives take on the character of soap opera figures, and the distinction between what is 'real' and what is 'imaginary' begins to disappear. The term postmodernity captures this social condition effectively.

For the policymaker and evaluator, one of the most intriguing and alarming characteristics of the postmodern condition is its permanent and irreducible plurality. Of course, plurality - surprising and disturbing differences between people - is the condition of all political life. It has always been an inherent in politics. In that sense it is not plurality itself, but the transformed social context in which plurality occurs that needs to be taken into account. I argue that under contemporary postmodern conditions plurality is permanent and irreducible: it cannot be reduced through the application of universal standards or by any form of authority. It is perhaps no coincidence that the demand that judgement be exercised in evaluation corresponded to a growing appreciation of plurality. It is true that values have been included in evaluation since it first emerged-the very term evaluation is linguistically rooted in the term value-but it was easy to overlook the extent to which facts are value-laden and that the delineation of objectives implies a unity of values. Plurality raises the question of whose values will dominate in an evaluation, or alternatively whether or not and how value differences will be negotiated.

Much of the upheaval today can be seen as a case of the rejection of plurality, a rejection whose hallmark is a kind of nostalgic yearning for 'simpler' times when 'family values' predominated and when everyone knew that 'what was so was so and what was not was not'. Modernist discourse is far from exhausted and a great deal of our practices are still being carried out in its name. In this article I argue, however, that modernism has lost its sense of lived validity and that the gains to be drawn from it are diminishing. Increasing numbers of people are not at ease with the old vocabulary and there is a desire for alternatives. In order to develop an answer responsive to our postmodern culture, I believe we should begin by trying to understand postmodernity as a social condition defined by its own distinctive features. 'Based on this assumption I would first like to explore the value of a new, responsive approach to evaluation that 'fits' with new kinds of decentralized, bottom-up and interactive styles of social planning that play with/in plurality.

This article begins with a rough sketch of the postmodern condition and postmodernist styles of knowledge production. The case of social revitalization in the city of Rotterdam is subsequently presented to illustrate what I believe to be a creative attempt by an entrepreneurial local government to revitalize their relationships with those living and working in the community. How one should evaluate such an innovative social program, given the dominant opinions in the evaluation literature, is discussed in the third section of this article. Having reviewed the situation as far as present day evaluation is concerned, I explore the possibilities of an evaluation approach that supports the decentralized, bottom-up and interactive style of social planning. This approach, known as responsive evaluation, is particularly appropriate to facilitate dynamic processes of sense-making and enables policymakers to fulfill their role as process-architect. The article continues with a reflection upon the possibilities to secure interaction and mutual understanding between social worlds and concludes with a description of the habit of mind and values that accompany these communicative concerns. 
The objective of this article, it must be emphasized, is not to provide an exhaustive interpretation of postmodernity and postmodernism. Its purpose is to present an accessible, yet critical, introduction to postmodernity and, in doing so, to highlight some of its implications for evaluation and social programming.

\section{The Gradual Transition from Modernity to Postmodernity}

We are being confronted with changes in our social condition, a condition which is sometimes referred to as postmodern. This postmodern condition has emerged in affluent Western countries during the course of the 20th century, and took a more definite form after the 1950s. Despite the fact that there is a lack of consensus as to the nature of postmodernity, most authors agree that it represents a reaction to, a departure from, or a continuation of modernity--the social formation that emerged in the West between the 17th and 19th centuries. This social order has to be understood in the light of the discovery that human order and morality were vulnerable, contingent and lacked reliable foundations (Bauman, 1992). The startled response to this revelation was the creation of a dreamlike image of the future and the exertion of considerable effort to place order and morality on a foundation that was at once solid, reliable and obligatory. Plurality, variety, ambivalence and contingency were now enemies to be destroyed. Order and morality had to be imposed to control social chaos and tame the immorality of human beings.

Modernist practices meant centralizing previously localized social power. But it was more than a transfer of power, it included changing the nature of power itself. Community-based social control, tolerant of different rather segmented lifestyles was subsumed in a state-based control that was consciously administered by specially trained experts. This state-based control had another way of dealing with plurality. It promoted supracommunal uniformity as an ideal and as a criterion for social improvement. Metaphorically speaking, this kind of authority can be called 'legislative' (Bauman, 1987). The modernist ambitions not only resulted in the transformation of power, they also led to changes in the use and character of knowledge/rationality: from a practical reason that incorporates moral deliberations to an instrumental reason that takes goals as given. This rationalization and progress of society could only be realized by objectifying the world. The world had, in other words, to be disembodied, despiritualized and disenchanted.

The universalistic ambitions of the modern state have inevitably led to a further weakening of the localized mechanisms of reproduction of previously autonomous ways of life. From the perspective of central power, plurality was defined as an obstacle on the way to the kind of society it projected. Popular, locally administered ways of life were defined as imperfect, immature stages in an overall line of development toward universal humanity. Traditional social structures broke down and new economic growth centers emerged. People moved there to secure jobs, away from their families, communities, and native countries, and away from the traditional institutions that had provided unquestioned frameworks for their lives. New multicultural countries were formed. Countries that once were culturally homogeneous have become multicultural, mixing races, ethnicities, religions and ideas.

The information society completed this transformation. Flexible forms of accumula- 
tion, characterized by the emergence of entirely new sectors of production, new ways of providing financial services, new markets, and intensified rates of commercial, technological and organizational innovation, have emerged to overcome the rigidities of postwar configurations (Harvey, 1989). The capitalist system in its consumer phase does not need (or only marginally needs) such traditional mechanisms to secure its reproduction. Seduction of the market and repression by professionals make legislation redundant (Bauman, 1992). To a certain extent the increasing power of the world's financial system has emerged to control capital flow at the expense of the power of the nation state. Today, the economic role of most governments boils down to maintaining hospitable local conditions capable of attracting stateless capital brokers (Bauman, 1993). The same process occurs in the cultural sector, where multinational corporations cross state borders. With the weakening of the State, traditional corporatist institutions have lost a great deal of their power, and many new types of mixed public and private configurations have emerged.

The gradual transition from modernity to postmodernity can be summarized as in Table $1 .^{2}$

In this particular culture, a postmodernist style of knowledge production could emerge. This particular discourse is critical of modernity as the ultimate designation of Western civilization, and goes further in suggesting that modernist ambitions are not valid today and very probably were not valid in the past either. From a postmodernist perspective plurality, variety, contingency and ambivalence are not seen as failures, but as evidence of the inadequacy of the efforts of modernist institutions to achieve universality, homogeneity, and clarity. Postmodernism does not try to transcend or counteract the void, but tries to live with ambivalence, contingency, variety, and plurality. These qualities are not seen as human fate, but rather as a sign and condition of humanity and morality. Postmodernists no longer expect to find the all-embracing, total and ultimate formula for the good life or for a society free of ambiguity, risk, danger and error. They are deeply suspicious of anyone who suggests otherwise (Bauman, 1993; Caputo, 1993; Nussbaum, 1990).

\author{
Table 1. \\ MODERN \\ national culture \\ emancipation politics \\ unity, sameness \\ organization, hierarchy \\ Fordist, mass-production \\ rationality \\ stable identity \\ guaranteed representation \\ the end of ideologies \\ pragmatism in politics \\ functionalism, 'glass boxes' \\ avant garde in art \\ radio-days \\ representation
}

\author{
POSTMODERN \\ creolization within global culture \\ lifestyle politics \\ plurality, differences \\ networks, reorganization \\ computer-aided customization \\ rationalities, 'we are all natives now' \\ mobile identities \\ ad hoc representation \\ variety of life forms \\ fundamentalism in politics \\ ornamentation, local street architecture, quotation \\ pop-art, collages, happenings \\ internet, MTV, CNN \\ simulation
}


The same is valid for the ontological foundations of truth and certainty: there are no meta-frameworks that exist outside time and place which can serve as an Archimedean point capable of validating objective truth (Bernstein, 1983; Rorty, 1979). There is no basic unit of matter that can be observed independent of those who make the observation. Language is not a medium between the world and statements about the world. It is an instrument with which reality is constructed (Rorty, 1989). The 'texts' that are the result of this 'writing' are not univocal or stable, but rather imprecise because the meanings of words are beyond their authors' control. Postmodernists, therefore, have abandoned the idea that they are Masters of their texts. They have also given up the idea of a rational, disembodied subject as the reference point for certainty, and instead try to explore new ways of thinking in which subject and object, emotion and cognition, mind and body are inextricably linked (Braidotti, 1991; Flax, 1993). They are critical of professional voices speaking for and inscribing others in a unified voice. Instead they try to develop hyphens between self and other by creating occasions when what is happening in their negotiated relationship can be discussed (Fine, 1994). A too ready assimilation of phenomena using given analytical and ready-made concepts is resisted by creating messy, open-ended, incomplete texts (Marcus, 1994). Hence, the crucial questions shift from the world as it 'is', to the world as it is socially constructed. Claims to truth, beauty and the life ideal are interpreted as the constructions of communities with particular interests, values and ways of life.

But what are the implications of this transformation to a postmodern condition for the practices of social programming and evaluation? Let us examine a case where a local government together with public, private and voluntary organizations and an evaluator have tried to face the postmodern condition that is in need of a new vocabulary.

\section{Social Revitalization}

In public relations campaigns the city of Rotterdam is promoted as having the largest harbour in the world and as being the economic, social and cultural center of the Rijnmond region. This image of the city as a center of economic activity is readily accepted when one catches sight of the glass box buildings of downtown Rotterdam, the ambitious plans for a Manhattan along the Maas and for a variety of other business and brain parks. The new technologies, implemented in the 1970 s and 1980 s to initiate economic innovation, seem to have had their effect. Several members of the Commission for Economic Innovation, however, were not satisfied with this economic revival. They were concerned that, despite the great degree of economic activity, the lives of certain groups, such as the city's unemployed, women and minorities, had not improved. Economic innovation, they proposed, should be complemented and corrected by social innovation. Social innovation was also seen as an appropriate response to the need to reevaluate the services and solutions created by the welfare state. Indirectly it seemed to provide an answer to the 'crisis of legitimation' government was facing at all levels: citizens who expressed their evident dissatisfaction by staying away from the polling stations or by voting for non-democratic and non-conventional parties; the growing distance between citizens and politicians and the negligible commitment of entrepreneurs to social problem solving. 


\section{Tineke A. Abma}

As a response, local government installed a commission: its task was to envision what social innovation might mean. Within the space of a year this commission had produced a document. It was based on four premises: (1) social innovation affects all inhabitants; (2) social innovation is a local rather than central affair; (3) the key to social innovation must be found in the redistribution of responsibilities between the state, the community, the citizens and the commercial sector; (4) social and economic innovation are interdependent. In the document, social innovation was loosely defined as 'a permanent process in which the revitalization of relationships between individuals, groups and organizations is increased, in order to enhance the quality of life of all Rotterdammers so that they can live in autonomy and harmony' (Idenburg, 1989). The term 'revitalization' aptly captures the idea that governments cannot plan urban social life by producing grandiose schemes, but they have to build on the social fabric that exists at grassroot level. If social revitalization was already high on the agenda, it became priority number one when a newly chosen local government was installed in 1990. Central government, which adopted the concept as their slogan supported social revitalization through territorial deregulation and decentralization.

Meanwhile, the Rotterdam social revitalization project leader-a charismatic personality who managed a small and temporarily installed project-bureau-translated the initial concepts of the commission into the document although he deliberately left several pages unwritten (College van Burgemeester en Wethouders, 1990). These blank pages were intended as a symbolic invitation that would encourage both citizens and entrepreneurs to come up with ideas that would make social revitalization a success." The project-leader: 'We focus on individuals who want to change, in spite of their formal position. We put an undefined term "social revitalization" in their hands and try to propitiate the societal climate for their initiatives.' Initiatives were stimulated by giving 'action bonuses'. If, for example, the inhabitants cleaned their street together, they could win an 'Opzoomer-prize' consisting of extra services. This prize took its name from the first street in which inhabitants had shown involvement with their neighborhood. What became known as the 'Opzoomeren' was such a success that a city-wide popular festival zcame known as tne Upzoomeren was sucn a success tnat a city-wide popuiar ies

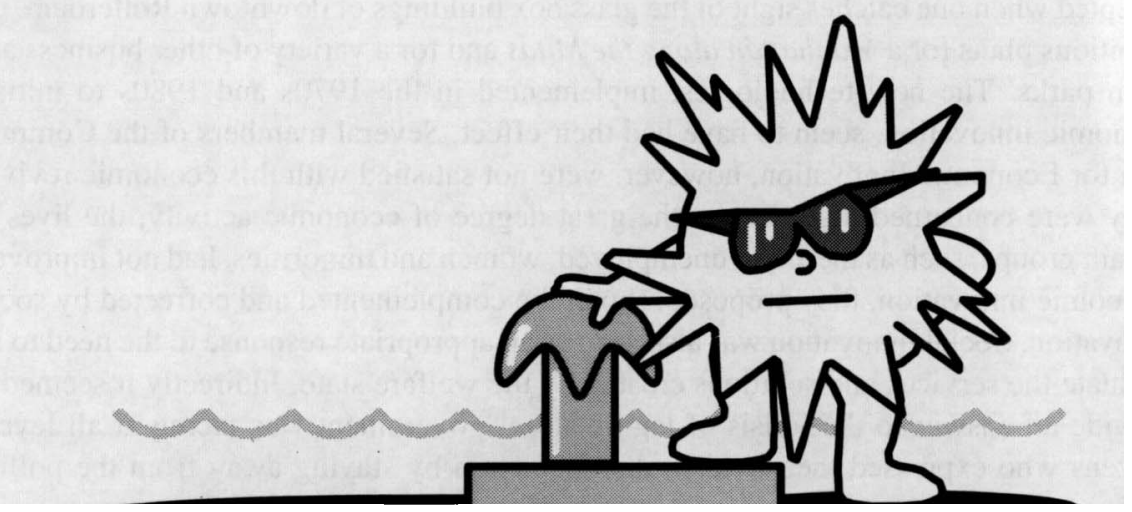

Figure 1. 'Oppie': Symbol of Opzoomeren. Reprinted by kind permission of Studio Stad. 


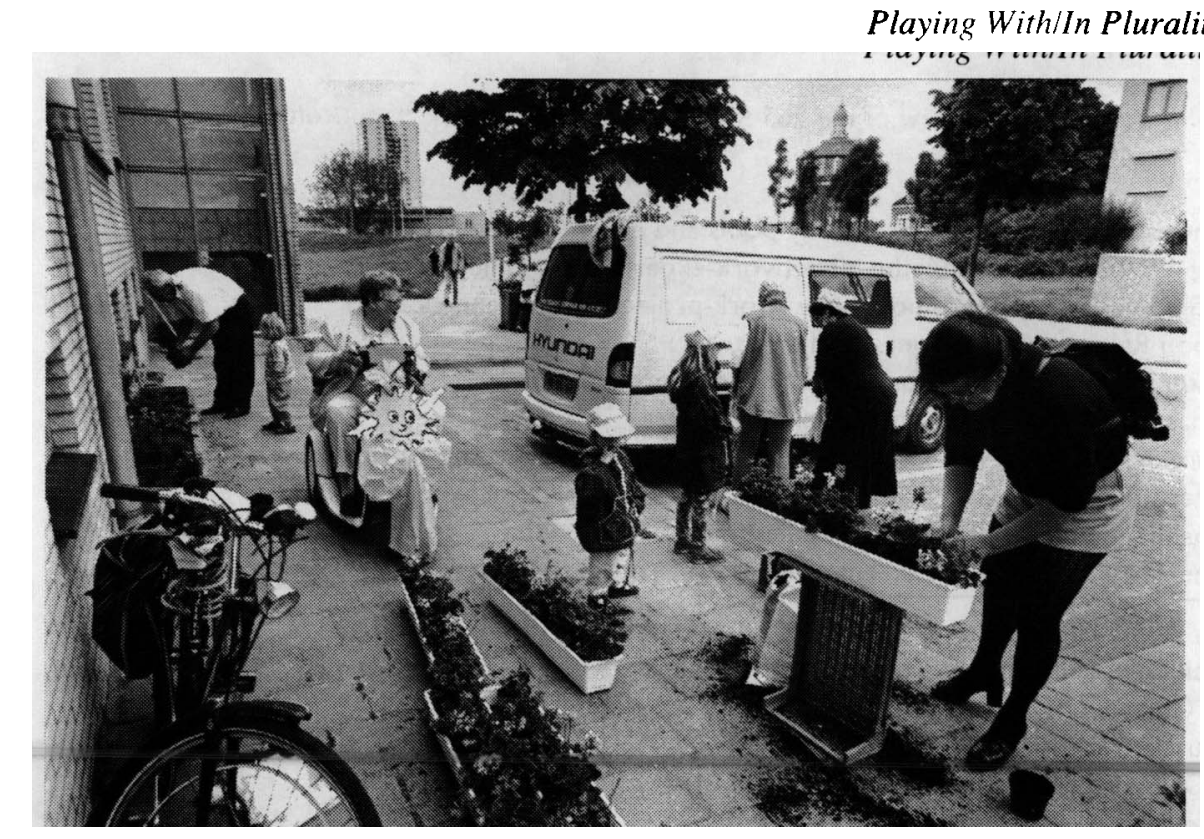

Figure 2. 'Opzoomeren' in Rotterdam. Photo reprinted by kind permission of Joop Reyngoud.

was organized in which more than 20,000 Rotterdammers participated (see photograph, Figure 2). 'Oppie' still is the symbol of Opzoomeren (see Figure 1).

Another initiative that attracted national and international attention was the creation of a labour-pool for the young, long-term unemployed to prepare them for the labor market. This initiative is the result of a successful public-private partnership. By creating low-skilled jobs in supermarkets, transportation and security, for example, youngsters were able to participate actively in society - an important condition for citizenshipand at the same time the public services were improved. In all these and other projects (see Table 2 for a global overview of the 265 projects) the local government takes an entrepreneurial role, searching for opportunities, empowering citizens and acting as a catalyst to private and voluntary initiatives. Some suggest that the confrontation between the world of public administration and business has stimulated tremendous creativity (Kensen, 1993; Osborne and Gaebler, 1992).

The initiative of this local government to invite inhabitants and others to revitalize the social fabric of the city illustrates a more general transition within planning and public administration (Frissen, 1996; Van Twist, 1994; In't Veld, 1995). The scope of planning becomes more global and less intensive; governmental interventions are reduced to make room for societal self-regulation by public and private organizations. The object of planning changes from content to policy-arrangements and texts; the government no longer acts as a central legislator, but fulfills the role of a process-architect who facilitates and stimulates sense-making activities. With regard to the level of planning one may observe that the one-sided attention for the macro-level is disappearing in favor of the re-valuation of the meso- and micro-level in society. This concerns local governments as well as community organizations and groups at grassroot level. The involve- 
Table 2. Global Overview of the 265 Social Revitalization Projects in Rotterdam

\section{Working}

Rotterdam Working (several labor-pools and education centers)

Pupil Workplace Old Mathenesse (work-experience in building trade)

't Sjoppie/Everything Almost New (work-project/secondhand clothes)

Abou Rakrak (work-project/clothing atelier)

Enterprise (training/assistance starting entrepreneurs)

Atlas (advice/assistance migrant-entrepreneurs)

Neighborhood Service Centre West (repair work by $55+$ and handicapped people)

Intesol (applying assistance for handicapped and labor-arbeidsongeschikten)

Cashba (day training alternative punishment)

The Third Wheel (bicycle repairs for the Third World)

Call Bus (transportation for elderly)

\section{Coring}

In Good Company (loneliness prevention for elderly)

Muscle 80 (sport-project)

YOUR Project (assistance for youngsters)

Scrap (creative use of waste-products)

Paulus Church (reception center for addicted)

En Route (active assistance youth)

Operation Play Well (quality improvement in children's reception centers)

Support Informal Care/Home Care (assistance and advice)

Learning

Step (interaction between mother and child)

Porch West (education-project for Islamic girls older than 12 years)

Prolonging Schoolday (collaboration between schools and welfare organizations)

Rotterdam Evening School (education for adults)

VIA South-East (information/advice adult education)

Project Integration Newcomers (reception center new Rotterdammers)

'Valentine' School (project reading-assistance/anti-deprivation in education)

Living

Prevention Team (education burglary prevention)

Opzoomerstreet (initiators Opzoomeren)

Children Cooking restaurant (neighborhood restaurant)

Dug out (meeting place for youngsters)

Green Fingers (maintenance private gardens, 55+ and handicapped)

Service 'Tarwewijk' Safe (safety project)

Car Park 'Slinge' (work-project/security)

'Maastunnel' project (work-project/security)

Restaurant 'Kenniet' (school restaurant)

KIDS (improving the external environment for children)

Source. College van Burgemeester en Wethouders, 'De inzet gevolgd, Eindrapportage project Sociale vernieuwing' (following the start, final report on social revitalization), February 1994, Rotterdam. 
ment within and perspectives of planning move in the direction of a multi-actor perspective and bottom-up approach. Instead of social planning based on analysis and instruction by experts, social revitalization is the product of extensive interactions and communication between a plurality of stakeholders. The next paragraph reconstructs the current state of affairs within evaluation in light of this transition within social planning and planning.

\section{Evaluation with Modernist Ambitions}

Formal evaluation came into being after the Second World War. Governments were more ambitious than ever to achieve planned changes in society. The conceptual development of modern evaluation has been strongly influenced by the ideals of social engineering that existed during the period when modernity was at its height. The ambitions of social engineering reflect the modernistic dream of imposing order through a strategy of instrumental rationality. Although evaluation is far from monolithic, the idea that social problems can be solved by an all-embracing government, enlightened by science, is still very much alive in current ideas on evaluation. It is generally accepted that evaluation serves to determine the utility, the efficacy and the cost-effectiveness of the policy choices available. Policy goals are taken as given and the evaluator is limited to the collection of data, thus providing - as a technically competent and politically neutral social science expert-the information needed by the decision maker. Evaluation, carried out according to the rules laid down in the scientific, hypotheticaldeductive method, will result in an accumulation of objective knowledge. This makes it possible to find a solution to almost any problem: scientific and social progress, rational approach and scientific knowledge are bound inseparably together.

One major problem which evaluators recognize but are not very willing to admit, is that social engineering ambitions have yet to be fulfilled. Evaluators insist that this is not because of any failure in the project itself. It is a technical failure that is not-yetresolved-but-in-principle-resolvable, a temporary imperfection on the road to perfection. Efforts made to extract the utmost from methodology should be understood in this context: they are grounded in the conviction that any failure of science-based social control must, in essence, be blamed on the flawed nature of the methods employed (Chen and Rossi, 1981; Rossi and Freeman, 1985). Another symptom of technical failure that has attracted considerable attention is the so-called 'under-utilization' of social science knowledge and of evaluation in particular. The driving force behind the development of those evaluation models which attempt to further perfect utility by drawing research and decision-making closer together, are rooted in the conviction that the function of evaluation lies in problem solving, and that its value is assessed on the basis of its direct, instrumental utility to decision makers (Patton, 1986, 1988).

By the late 1960s and early 1970s this kind of evaluation came under criticism from writers who pointed out that trying to deliver information 'just-in-time' for use in the decision-making process turned evaluation into a technology. (MacRae, 1976; Rein, 1976). These authors claimed that the profession was not required to be critical of goals and values and therefore was primarily concerned with the question of technical rationality, i.e. how to propagate and implement those procedures which would serve 
bureaucratic management the best. Furthermore, the dominant approach was criticized for being utilitarian. A lack of moral responsibility concealed under a guise of neutrality was also problematized with reference to the policies and goals that have resulted in some of modernity's less illustrious legacies. The problem of 'underutilization' was not only ascribed to a misfit between the worlds of science and policymaking, but understood as neglect of an adequate response to the valuedilemmas, such as the Vietnam War, that plagued American society. Evaluators were not able to explicate or answer questions concerning the goals/values that were governing the policies. Another problem that caught the attention of these authors was the way the instrumental reasoning of experts was colonizing the life-world.

Because conventional methodology could not address these problems, some began to explore how a 'normative' discourse could be integrated into empirical modes of analysis and how the current domination of experts could be corrected through the participation of lay people (Fisher, 1980; Fisher, 1990; Fisher and Forester, 1987; House, 1980, 1991). Fisher (1990) for example proposes a 'logic of critical evaluation' in which a policy is systematically questioned on four points: (a) 'technical verification' is concerned, at an empirical level, with the effectiveness and efficiency of a policy in achieving its objectives; (b) 'situational validation', taking account of the values of specific contexts, is concerned with the relevance, consistency, and priority of policy objectives; (c) 'systems vindication' assesses the broader consequences of policy commitments for both the salient ideals and actual operations of a given social order; (d) finally, at the level of 'social choice', one asks whether an established social order is legitimate and whether an alternative is justifiable. In this methodology policy goals are not taken as given, but evaluated on their merit in the light of higher values (for example equity or justice) and their value in relation to the situational context. The subjective experiences of lay people are taken into account, but experts maintain a special status.

\section{Incompatibilities: Modern Evaluation and Postmodern Planning}

One can have serious doubts whether a traditional evaluation approach 'fits' with the communicative concern of social revitalization (Vanderplaat, 1995) and the postmodern style of social planning more in general. When the local government-in the person of the project leader-asked for an evaluation, the concept of social revitalization was still open. According to the dominant evaluation approach, when there is an innovational program, the evaluator should explain the program's goals, means and inputs, and ultimately rationalize the theory behind the policy in terms of social science theory. She or he should also develop valid instruments and set up a quasi-experimental design. An approach grounded in critical theory would involve the evaluator adding a normative analysis of the program goals to this instrumental rationality.

In the case of Rotterdam the evaluator, in the person of Kees Fortuin, felt that the lack of clearly specified goals not only presented methodological problems, but that both approaches were in contradiction to the new interactive style of social planning being promoted by social revitalization. As already stated, social revitalization was introduced by local government in order to encourage citizens and entrepreneurs to bring forward 
their ideas and visions on local innovation. The design of a model with certain measures as outcomes for effectiveness, efficiency and justice would have undermined the plurality of values, rationalities and lifestyles practised by the various actors involved. The evaluator wanted to honour the plurality of values and meanings. In his eyes social revitalization was not a 'program' in the sense of an instrument being used to achieve a given end, but a discursive practice in which meanings are created, contested and transformed in the interaction between different stakeholders. When these meanings are enacted they become real in their consequences. From this social constructivist perspective the central question is not whether social revitalization is effective, efficient or just, but how social revitalization is constructed in interactions. For responsive evaluators interesting sub-questions are: whose meanings become dominant, whose voices are not heard, and how can contexts be created for those silenced voices (Lincoln, 1993).

The problem of how one evaluates multiple realities grounded in a plurality of values was in this case complicated by the fact that the evaluation was taking place in a political setting where the evaluator had to deal with agents-sponsors and policymakers - who had their own ideas about how an evaluation should be conducted. In this case the evaluator was able to create a space to experiment with an evaluation approach that did fit with the communicative concern of social revitalization and was substantially different from dominant approaches. Several people in the policymaking arena were convinced that a 'product' evaluation was probably important but the primary concern was whether or not the 'process' of social revitalization was perceived and experienced as being successful. They agreed that information on the number of unemployed people receiving education or getting a job, and decreases in crime and illiteracy would be too limited to give an insight into the value of social revitalization projects. There was a felt need for more enriched data that incorporated the lived experiences and meanings of those who were involved in the process of social revitalization. Politicians expected that this information would get them more in touch with the city and enable them to make more informed decisions about the worth of new initiatives. This created the opportunity to invent a different kind of evaluation, one that is sometimes called 'responsive'.

\section{Responsive Evaluation}

Responsive evaluation has a long intellectual history and this is not always fully recognized. The methods used reflect a more hermeneutic interpretation of social science than the social constructivistic persuasions that have appeared more recently in the social sciences and philosophy (Schwandt, 1994). Guba and Lincoln (1981, 1989) have probably played the most prominent role in systematically recording and disseminating this, but they give full credit to Stake (1975) as the originator of these ideas.

In responsive evaluation, the criteria used to determine the worth of a particular situation are not set or 'pre-ordained' beforehand. Rather they emerge from the specific social contexts of various stakeholders. Values, in other words, are relative to their social context. Responsive evaluation focuses on the plurality and transformation of non-commensurate values. Values have their origins in the messages and meanings implicitly conveyed in the conversations and customs of daily life. An evaluation is 


\section{Tineke A. Abma}

responsive when it takes the values discussed and practised by various actors as a point of departure. It focuses on the 'concerns' and 'issues' of all stakeholders, including 'agents', 'beneficiaries' and 'victims'. A 'concern' can be interpreted as a valuedisjunction, that is, a respondent constructs a situation that is inappropriate from the point of view of the set of values that he or she holds. A respondent may, for example, be worried about the fragmentation of social life, because she or he finds community and solidarity highly important values. An 'issue' implies a controversy-two or more points of view resting on different positions taken on the bases of the same value (actors may, for example, come to different interpretations based on the efficiency of a program because their standards differ) or a conflict arising between different values (for example between efficiency and solidarity).

Responsive evaluation gives a description of values and the socio-cultural context in which these values are embedded. It is multi-voiced, because it lakes the perspective of the stakeholders themselves as the starting point for evaluation. Furthermore, it tries to effect a conversation between authentic voices inhabiting different socio-cultural contexts. It is through a 'hermeneutic-dialectical process' in which meanings are contested that the evaluator and stakeholders together set up an 'agenda for negotiation' that will direct evaluation. The vitality of that process will depend upon the conditions being created which allow an interplay to occur. In the first instance, this means that all stakeholders have to be able to participate in the process, and that their concerns and issues are heard. The second step comes with accepting and understanding the plurality entailed in the social context. Thirdly, it is necessary to construct some sort of vocabulary which can express this plurality. The evaluator attempts to increase the level of personal and mutual understanding: 'all parties are likely to have reconstructed the constructions with which they began. This is so even when consensus is not achieved. All parties are thus simultaneously educated and empowered' (Guba and Lincoln, 1989: 149).

Responsive evaluation tries to document the uniqueness of an object and to achieve understanding of a particular aspect of human experience as it is experienced, lived or felt by those participating in that experience. Thus Stake (1991) states that evaluators must exchange their scientific-technical spectacles for socio-anthropological ones. This does not mean that the evaluator should apply theoretical concepts borrowed from anthropology. What concerns Stake is anthropological sensitivity, a feeling for the concrete experiences of people, for the activities they develop over the course of time and for their physical and social environment. Context and experience are approached as a complex temporal, socio-cultural and geographically specific entity. The evaluation is limited to a particular 'setting', because an experience has significance only within a particular context. This setting should occur naturally and not be manipulated, hence the tag 'naturalistic' research. It enables the evaluator to collect idiosyncratic data. In other words responsive evaluation is highly situationalist, and this offers the opportunity to tune in to unexpected transformations in values.

The selection of particular settings is an aspect not found in the conventional approach to generalization and sampling where the approach is based on the assumption that social life is stable and can be fixed in linear causalities and propositional laws. If, however, one assumes that: (a) our social life is in a constant process of transformation because of 
human reflexivity and human agency; (b) its confusing complexity can never be fully explained and predicted in linear causalities in the sense that situations are undetermined by the past and not determining for the future; and (c) even if we could discover standard therapies for the solution of social problems, these would be interpreted in different ways depending upon who interpreted them and the situation in which they were interpreted. It is therefore more meaningful to construct highly contextualized descriptions of particular situations. This does not imply that we cannot learn from highly particularized descriptions of specific situations, or that these 'thick descriptions' cannot be transmitted (or applied) to other contexts (Stake and Trumbull, 1982).

The point is that an informed decision about the possibility of transfer from one context to another can only be made by the reader, who unlike the author knows the special context to which knowledge is transferred. To be able to provide the reader with context-bound knowledge that enhances understanding in the sense of a greater variety of meanings, the evaluator has to make an informed selection of 'samples'. The preferred sampling procedure is maximal variation: the evaluator starts with a certain 'sample' - either a respondent or a situation-and having gained insight into the 'sample' the evaluator goes on searching for 'samples' that maximally contrast with his or her first sample (Lincoln and Guba, 1985). This process can go on for several 'samples' until eventually saturation is reached where no additional meanings can be found. In responsive evaluation both quantitative and qualitative methods can be employed, but there is a preference for qualitative methods because qualitative data are more appropriate to represent the plurality, dynamics and context of meanings (what sense does it, for example, make to count 'interaction'? Frequency of contacts does not say anything about the lived experiences of people).

Within qualitative methods the evaluator constitutes an important instrument, since he or she is able to react immediately to situations and is able to observe a richly patterned reality using what is known as tacit knowledge (Polanyi, 1966). The concept of tacit knowledge suggests that one can possess knowledge of an object without being able to specify all the elements used to construct that knowledge. Besides the knowledge of unspecifiable elements, a responsive evaluator uses emotions as an intelligent part of ethical agency, responsive to the workings of deliberation and essential to its completion. Responsive evaluators do not see themselves as objective, authoritative, politically neutral observers who stand outside the hermeneutic circle. Rather they work actively to develop a transactional relationship with the respondents on the bases of a participatory mode of consciousness (Heshusius, 1994).

The ultimate goal of responsive evaluation is to present a series of fruitful interruptions that demonstrate the multiplicity of meaning-making and interpretation. There are several methodological conventions the evaluator can follow to increase the trustworthiness of her or his findings (Guba and Lincoln, 1989). First and foremost the evaluator has to practice reflexivity. Reflexivity is more than a form of self-critique or personal confession. The evaluator is required to actively reflect on the way his or her position and possible partiality affect the representation. Another important procedure is called member checking. Checking interpretations with the respondent during or after an interview gives the respondent the opportunity to make corrections and to clarify ambiguities. This can add breadth and depth to the study and makes the evaluator more 
careful in her or his interpretations. Member checks create spaces for counterinterpretations and in doing so increase the variety of meanings.

In responsive evaluation, findings are written up in a narrative rather than a propositional mode. This is not only a matter of style, but a strategy that is informed by epistemological and political deliberations. A too-easy assimilation of a phenomenon may exclude the possibility of making other, more meaningful interpretations and utility requires the recognition of the interpretative power of the readers and users. In order to reflect upon personal and day-to-day knowledge, use is made of 'natural' language. Not only those who have experienced the process but also those who have not had direct experience of it must be able to gain insight from the content into what has been going on and how significant it is for those involved. The material should provide what has been called a vicarious experience. Vicarious experience takes the place of direct experience and is expressed in terms of persons, places and events. It consists of stories which, because they further construct upon the human condition, can affect participants directly.

The plurality and diversity of meanings represented in a story enhance vicarious experience. They enable readers to experience the program from different insiders' perspectives and can be used as a starting point for discussions between stakeholders. An 'agenda for negotiation' in which the controversial issues are listed may facilitate this process. And, as said before, these discussions do not necessarily result in consensus. Conflicts may arise and the evaluator faces the challenge to handle the situation. The generated variety serves here as the source to prevent binary oppositions: the introduction of other points of view creates the way for a more interesting discussion. The process of generating variety may at least result in a more sophisticated understanding of the meanings of the program. Meaningful participation is worth the effort, because it (a) broadens the scope of the evaluation with knowledge from experts, i.e. those who actually experience the program; (b) builds trust and maintains commmitment of users, i.e. those who have to apply and adapt the results to their own situation (Greene, 1987); (c) gives a voice to stakeholders, i.e. those whose interests are at stake.

\section{Realities and Relationships in Rotterdam}

In the context of social revitalization in the Rotterdam metropolitan area, three settings were evaluated: 'de Kop van Zuid', 'Het Nieuwe Westen', and 'Hoogvliet'. These sites were already marked as special 'social revitalization action areas' in the document on social revitalization. The most important criterion used in their selection was that they be as different as possible from each other. In retrospect the following set of criteria appear to have played a role in selection: (a) Socio-geographic space. Hoogvliet is a small town almost 30 kilometers from Rotterdam, Het Nieuwe Westen is an inner city neighborhood in Rotterdam itself, and de Kop van Zuid and the neighborhoods which surround it make up one district on the south side of the river Maas; (b) The need for social revitalization. Hoogvliet needs support in attempting social revitalization, but this is not always recognized by locally elected politicians. Het Nieuwe Westen is known as a traditional, 'backward' neighborhood, struggling with urban renovation. 
However, social-welfare agencies are actively seeking a new role there. De Kop van Zuid tried to initiate social revitalization through economic innovation; (c) Leadership. In Hoogvliet the local government plays a leadership role in social revitalization, in Het Nieuwe Westen social welfare agencies are developing authority, and in de Kop van Zuid agencies made up of the local population are leaders in social revitalization. In line with our earlier discussion on sampling, we can say that these sites display the necessary variety.

\section{Three 'Social Inventions'}

The evaluator entered these settings with the following open questions: Which actors are developing authority in the three action areas? What resistance is there? What kinds of social action are being created? (Fortuin, 1991). In the first half year the evaluator tried to gain an entree into the neighborhood, build up trust and familiarize himself with the different settings. He spent time in the neighborhood, talked to the people there and analyzed several documents. After this global exploration of the three areas the evaluator composed a report detailing the history of social revitalization in each area, the actors taking part, their interaction, network, and their concerns. On the basis of a discussion about the credibility of interpretations with those involved, the evaluator invited stakeholders to select a set of initiatives they labeled social revitalization. ${ }^{5}$ In Feijenoord, one of the neighborhoods in the Kop van Zuid, Punt 50 was chosen. Punt 50 is a multi-functional center specializing in lending toys and equipment, and providing health information and child-rearing support. It is run by a group of poorlyeducated women with the help of social welfare professionals. In Het Nieuwe Westen the project chosen by the stakeholders for evaluation dealt with labor-rehabilitation. In Hoogvliet it was a project concerned with making the neighborhoods livable.

In the following section I will describe these 'social inventions' to give readers an idea of the initiatives undertaken in the city, how these were evaluated and what the results were.

\section{'Punt 50'}

Some call it a toy library, others an information or health service center and for others it is a place where the women in Feijenoord can meet each other. Punt 50 can also be defined as a social revitalization project, the working place of one of the labor poolers or as one of the most successful projects of a Healthy City policy and thus as part of an international Healthy City network that is related to World Health Organization initiatives (Fortuin and Hovingh, 1992: 23).

In Feijenoord, a group of poorly educated women took over responsibility for a toy library in danger of being closed down. Every week for many years they had visited the neighborhood center, but were never actively involved in their neighborhood. In retrospect one may say that they needed these years to develop identity and selfawareness, to form a group and to become interested in their social environment. Once 'ready' the women actively invested in the place. They did not just continue the toy library, but appropriated it and adapted it to their own values and desires. As a result the service package was extended to the lending of tools and expensive household appliances and child-rearing support. At about the same time the 'Gemeentelijke 


\section{Tineke A. Abma}

GezondheidsDienst' (GGD) (the city health authority) was implementing projects inspired by notions of WHO's Healthy Cities program, including the empowerment of citizens and working at grass-roots level. The GGD was looking for a suitable place and when they presented their plan for a health care information project the women offered them a site in Punt 50. Furthermore the women developed relationships with organizations and residents in their neighborhood, and as such Punt 50 became a sort of crystalization-point that attracted other actors and initiatives. It became an important symbol for social revitalization particularly for women. These volunteers showed that it could be self-rewarding to become an active citizen.

Although Punt 50 embodied different realities, the reality of Punt 50 as a health information project came to dominate in policy circles. This is not so suprising, because the social world of the GGD fits well with that of policymakers. In both instances it is, for example, self-evident to make a distinction between 'health care' and 'welfare' interests. The women who started Punt 50 considered the fact that Punt 50 became known as a health information project to be a great threat. They were afraid that the success of the project would primarily be measured in terms of health care achievements. Such an assessment would fail to do justice to the achievements of the center as a whole. The women felt frustrated and angry about this and wanted to reclaim ownership. Another source of frustration was the collaboration between the women-volunteers and the professionals of the GGD. The professionals' points of view differed significantly from the volunteers' point of view. Volunteers listened, for example, to the whole story told by the client who came for a health brochure, professionals on the contrary were very eager to reduce the story to what they thought was important. Volunteers took more time for coffee-breaks and had different rhythms from professionals. These differences created tensions, and if social workers had not paid attention to mediating between the two social worlds these tensions could easily have resulted in longstanding conflicts.

\section{'ABC Project'}

In Het Nieuwe Westen the neighborhood support work prompted a project for the longterm unemployed to help them take on socially useful activities. The fact that a social welfare organization rather than a labor market-related organization took the initiative was not without meaning. The activities people could develop and the goals of the project were not strictly defined in terms of paid work, but also included voluntary work, training and leisure activities. The project distinguished itself from other projects, because the clients themselves decided whether they wanted paid or unpaid work and what social activity they wanted. Other organizations usually work on the basis of rather narrowly defined objectives from which the client is not supposed to deviate. The $\mathrm{ABC}$ project gave its clients the opportunity of going through a process of orientation and did not push them in any particular direction. Another important aspect was the informal culture of the project. Clients could drop in without making appointments, cases were not formally closed, the front door was not controlled. Most project workers knew their clients.

The ABC project activated the orientation process of clients, and as a result, the unemployed themselves became much more active in working on their own future. 
Many of them opted for a paid job after they had gone through this process. Over one third of the project's clients - previously considered prospectless-managed to find paid jobs. With its approach the $\mathrm{ABC}$ project succeeded in reaching the long-term unemployed who could not be reached by any other organization. Less successful was the collaboration with the 'Gemeentelijke Sociale Dienst' (GSD) (the city social service), a city-level organization. Although this organization was initially eager to send their clients to the $\mathrm{ABC}$ project nothing in fact happened. Initially the professionals working at the GSD were unwilling to make referrals to an organization that they perceived as 'unprofessional'. Later on, they changed their attitude, but the majority of the clients of the $\mathrm{ABC}$ project still came via neighborhood community centers and word of mouth.

\section{Neighborhood Management}

The neighborhood management project played a vital role in social revitalization in Hoogvliet. The aim of the project was to maintain the physical and social climate in a neighborhood by encouraging collaboration between residents, municipal services and neighborhood community services. Neighborhood committees were set up on which representatives of many of those involved had a seat. The committees had an administrative role and voiced their opinions on the future of the neighborhood. As such, they were appropriated as vehicles for bringing government closer to citizens by the district municipality of Hoogvliet. In addition to these committees, administrative community centres were established in an attempt to create one 'counter' for all the services working in a particular area. Residents' complaints and ideas could also be taken to the centre. All in all this enabled the services to work from the perspective of an integrated approach to neighborhood problems. Each neighborhood had a neighborhood manager who worked for the 'Bureau Beheer' (Neighborhood Management Bureau) carrying out the project. The government's desire to improve their communication with citizens appeared to be a difficult one to realize. In those neighborhoods where residents came from different national cultures, professionals faced the extra challenge of meeting people without a purpose, and valuing the encounter more than simply getting things done.

From the start the project was framed within a broad conception of neighborhood management. Those involved believed that technical and social processes should go hand in hand. The city of Rotterdam, on the other hand, adopted a narrower interpretation, symbolized by the slogan: 'A neighborhood should be clean, safe and whole'. The differences in the approach created tensions, particularly because people in organizations anticipated the criteria that serve as measurements for their behaviour:

There have been complaints by inhabitants bothered by speeding cars and they demand speed ramps ... The speed ramps are not realized. A lot of energy goes into solving the problem. The police do a lot of work-everyone puts in considerable effort. In the end it may well have been cheaper to build speed ramps and easier too! There is a political gain, but how does one measure such performance? ...

The moment a policeman tells local people who complain about speeding cars that there should be a speed ramp in the road, work is created for the public works department. This should not happen, because the policeman on the beat should be able to solve the problem 
himself. However, the local policeman knows only too well that he is unable to do this because the person speeding in his BMW is a known drugs dealer and as soon as he is reprimanded he will use his gun. He'll pull his pistol on the other inhabitants too. This is why the local policeman tells the people to get a speed ramp ... and the problem will be solved. There is, of course, no one who is able to solve the problem efficiently and we are confronted again by the nature of the output question....

Different values competed: economic rationality came into conflict with other rationalities, and this had serious implications for the quality of life and the safety of the neighborhoods.

\section{Frictions between Relationships and Realities}

What an evaluation of all these 'social inventions' shows is that the desire of governments to involve citizens and other stakeholders puts pressure on the valueframework underlying conventional policy practices. Tensions stem from the frictions between social worlds, understood here as a loose coupling of stakeholders, their realities and rules of interaction. The evaluator describes what happens when different worlds meet or fail to meet, the way in which one culture tends to dominate another and how and with what consequences certain meanings become excluded from an ongoing discourse. Although plurality refers to differences between groups of people, our attention is drawn to the fact that individuals can never be reduced to fixed categories. People are involved in a variety of worlds, and this multiple inclusion makes it possible to talk between worlds. In Punt 50 the friction between volunteers (women who see Punt 50 primarily as a meeting point), and health care professionals, who see Punt 50 as a health service point, are 'mediated' by social welfare workers who are included in both worlds. The evaluator showed the intersections between social worlds. By presenting the lived experiences of these women and the professionals, the evaluator defined himself as a 'translator' (Fortuin, 1994a, 1994b; Fortuin and Hovingh, 1992). His aim was to restore the distorted communication and interaction between social worlds.

In the next part I reflect upon these distortions and the possibilities of an evaluator to revitalize social relations.

\section{Multiple Inclusions and Intersections between Worlds}

We are living under postmodern conditions where plurality has become more central and problematic. People can no longer be categorized into homogeneous groups. Representation of plurality through collective democratic and corporatist decision making is becoming increasingly problematic, and the consequences are disturbing many politicians. The relationship between government and citizen is sometimes characterized as a 'gap'. The gap-metaphor suggests that there is no way the people on each side of the gap can interact with each other. The world of the government and world of the citizen are far apart and do not intersect. There are no bridges that link them. Each is fixed in its own world and cannot speak the language of the other. The problem is that this metaphor becomes reified.

From a social constructivist perspective we may experience worlds as being 
homogeneous in the same way as we may experience reality as being something hard and fast because, as human beings, we tend to underplay variety and dynamism. We reach a temporary settlement over what is involved in a particular situation and decide how we want to interact and with whom. This provides a temporal stability and unity which enables us to interact with each other without too much discussion. The reproduction of practices may, however, lead to fixations when people systematically exclude other constructions, other actors or other interactions. Worlds are not homogeneous but they become homogeneous and isolated because we exclude variety and dynamism. Isolation may give us a sense of stability - 'I am safe in my own world'-but it is not very fruitful because it locks us up in this world of ours and reduces us to being 'one' instead of 'many'. In the most extreme case isolation may lead to such phenomena as racism and nationalism. It is the construction of the category of 'other' - sometimes called the practice of 'othering' - that gives us identity and superiority, and this process lies at the heart of all 'gaps' and disconnections. When the 'other' has an essentialistic identity that is given and totally different from self, we are no longer in any relation with him or her. We are then mutually exclusive (at least we think we are).

In reporting on social revitalization, the evaluator drew attention to the fact that there are differences between worlds, but that these differences are not absolute. Worlds are not completely homogeneous; they are always more or less heterogeneous. This is so because worlds are reproduced by actors who themselves inhabit different worlds and languages. This multiple inclusion opens the possibility that actors transfer social meanings or interaction rules from one world to another. As such it is an important source of social dynamics (Termeer and van Twist, 1991). It refers to the insight of postmodernists who point out that dissension or conflict and not consensus or harmony is the motor for change. The embeddedness of an actor in a plurality of social worlds also offers opportunities for negotiations between different worlds. In Punt 50 the social workers recognized themselves in the world of the volunteers and the world of the professionals. Being multiple meant they were able and willing to work at the intersections between worlds. The concept of intersectionality captures the way in which the particular location of a social worker in Punt 50, for example, is unique and in some sense cannot be assimilated into the discursive paradigms of professionals and volunteers.

Describing multiple inclusions and intersections between worlds is, I think, extremely important and can be highly effective in terms of restoring distorted communication and facilitating ongoing interactions. It is important, because the more we talk about worlds being homogeneous, the more we tend to believe that we are actually talking about the way 'things really are'. To think in multiple inclusions and intersections is effective because it is a positive way of dealing with a tendency to construct absolute opposites. Thus responsive evaluation may provide politicians and civil servants with in-depth insights that will help them to stay informed about the value transformations in a particular socio-cultural context. In addition this source may become the basis of a way of bridging the socially constructed 'gaps' between government and citizens. But what should an evaluator do in the process of evaluation when mediators like the social workers are absent and relations are fixed? How can 


\section{Tineke A. Abma}

blocked interaction be opened? As an agent for change, one may intervene actively by suggesting the introduction of an actor with low inclusions in both worlds. Low inclusion means having a commitment and relation to both worlds, but not being highly engaged. The introduced actor will have the greatest impact if the intervention is not 'ad hoc' but more durable. This actor may introduce other, not dominant meanings and/ or interactions from other social worlds which may re-open and facilitate ongoing interaction (Van Dongen, 1991). ${ }^{6}$

\section{Reception of Responsive Evaluation}

What the responsive evaluation of social revitalization in the city of Rotterdam clearly shows is that the desire of governments to revitalize their relationships with people can only succeed if those working for the government are willing to put the realities of their policies and rules of interaction at least temporarily on one side. And although this 'message from society' might be challenging, the evaluation of social revitalization was in general well received among policymakers as well as other stakeholders. How can this reception be interpreted? Kaplan (1986) suggests that policymakers live in stories. They prefer to directly observe events crucial for their policies. This is an impossible mission. Evaluators able to present policymakers with a vicarious experience of those events are of great value. Their case studies bring them into contact with what goes on in the hearts of people and offers them a fund of rich stories and juicy anecdotes. Intrinsic case studies keep policymakers in touch with a plurality of realities and ideas. The Rotterdam city council considered, for example, the formulation of an 'activating support work policy' based on ideas developed in the $\mathrm{ABC}$ project. Other stakeholders valued the approach, because it recognized their realities.

In general one might say that people will be more open to responsive evaluations if the underlying values resonate with their personal values and the values underlying the policy program and the organizational context. Important values that underpin responsive evaluation are reflexivity, playfulness and responsiveness. Reflexivity means critically reviewing the way one's position influences the knowledge generated. How does the evaluator, for example, claim authority and how is it that others are willing to accept that knowledge? Reflexivity is related to the value of playfulness. A playful person is not too attached to his or her personal persuasions and appreciates the power of redescribing, the power of language to make new and different things possible and important. This appreciation becomes possible when one's object is defined by an expanding repertoire of alternative descriptions rather than The One True Description (Rorty, 1989). Responsiveness means listening and responding to others in such a way that one not only enters the reality of another person, but also changes one's own. It is an attitude that transforms realities through the experience of a relationship.

This raises the question of whether we can learn to value reflexivity, playfulness and responsiveness, and how we are to create organizational contexts in which these values can flourish. Answering these questions drives us into a paradox: these are values that cannot be achieved instrumentally. 'The type of solidarity, communicative interaction, dialogue, and judgements required for the concrete realization of praxis already presupposes incipient forms of community life that such praxis seeks to foster' 
(Bernstein, 1983: 175). Given the demands by most state agencies for manifest and quantifiable outputs from funded interventions and the concomitant pressure on evaluation studies to work within this frame and indeed respond to it, it is quite justifiable to be critical and concerned about the prospects for responsive evaluation. In our technocratic society we are (still) obsessed with objectivity, efficiency and optimal performance (Abma, 1993). These typical modern values put considerable pressure on the values that are vital for relationships, such as reflexivity, playfulness and responsiveness. But despite the trends towards a further rationalization of our culture, the case of social revitalization in Rotterdam shows that there are places where there is room for creative experimentation. Here people are making the first steps towards developing vital realities and relationships. Responsive evaluators can join these players with/in plurality.

\section{Notes}

First and foremost $\mathrm{I}$ want to thank Kees Fortuin who invited me to evaluate his evaluation of social revitalization in Rotterdam. An earlier version of this paper was presented at the international conference 'The Transformation of Values in Pluriform Society-Steering Perspectives for Government and Public Policy', organized by the Faculty of Public Administration, Erasmus University in Rotterdam, February 1995. This conference enabled me to discuss and develop my ideas in a friendly context and I thank Roel in't Veld, the organizers and participants for the interest they showed in my work. Thanks also to Sandra Kensen for her insights and support. In addition, I would like to acknowledge the influence, friendship and support of Egon Guba, Jennifer Greene, Yvonna Lincoln, Thomas Schwandt and Robert Stake. Finally, I wish the 'Opzoomer Mee' team and inhabitants of Rotterdam good luck with their efforts to vitalize their realities and relationships.

1. This refers to the much debated question between historians, sociologists and philosophers as to whether this time is so radically new that it depicts a new epoch, a transitory phase, or a continuation of modernity. Jameson (1991) offers us another view. According to him, postmodernity is a contingent reaction to capitalism, a cultural domination (not an option) that requires a re-invention of ourselves and our practices.

2. This table is a transformation and an extension of the one contemplated by Herman van Gunsteren (1992).

3. In 1994 the project-bureau for social revitalization delegated their tasks to the local municipalities. In the accompanying letter to the council, the Mayor and Councillors conclude that 80 percent of the objectives set out in 1990 have been realized, several projects have been accelerated (e.g., Project Integration Newcomers), others have been slowed down (e.g. Rotterdam Work) but still received full attention. The response of society was much greater than expected. In 265 places in the city social revitalization has been localized. Almost 40,000 citizens have been activated, and this figure does not include the users of the Rotterdam Pas $(50,000)$, the 600 Opzoomerstreets (if 20 citizens are active per street this makes 12,000 persons) and a hard core of 14,000 volunteers.

4. The word sample has been put into quotation marks because this sampling procedure differs from conventional ways of sampling where the goal is to generalize knowledge from a representative sample to a larger population.

5. The sampling design gradually emerged: as insights and information accumulated and the evaluator and stakeholders worked together to generate a variety of meanings, the sample 


\section{Tineke A. Abma}

became more and more focused on the issues that seemed most relevant to stakeholders in the given situation.

6. For a more detailed theoretical explanation and illustration of several other creative strategies in relation to otherness, see Abma, 1996.

\section{References}

Abma, Tineke A. (1993) 'Beyond the Technocratic Orientation in Policy Evaluation', paper presented at the 11th European Group for Organizational Studies (EGOS) Colloquium, The Production and Diffusion of Managerial and Organizational Knowledge, Paris, 6-8 July.

Abma, Tineke A. (in press) 'Playing: Creative Strategies to Manage Differences in Evaluation', in L. Mabry (ed.) Beyond Qualitative Evaluation, New' Directions in Evaluation.

Bauman, Z. (1987) Interpreters and Legislators. On Modernity, Post-modernity and Intellectuals. Oxford: Polity Press, Blackwell.

Bauman, Z. (1992) Intimations of Postmodernity. London and New York: Routledge.

Bauman, Z. (1993) Postmodern Ethics. Oxford: Blackwell.

Bernstein, R. J. (1983) Beyond Objectivism and Relativism. Oxford: Blackwell.

Braidotti, R. (1991) Patterns of Dissonance: A Study of Women and Contemporary Philosophy. New York: Routledge.

Caputo, J. D. (1993) Against Ethics. Contributions to a Poetics of Obligation with Constant Reference to Deconstruction. Bloomington and Indianapolis: Indiana University Press.

Chen, H. T. and P. H. Rossi (1981) 'The Multi-goal, Theory-driven Approach to Evaluation, a Model Linking Basic and Applied Social Science', in H. E. Freeman and M. A. Solomon (eds) Evaluation Studies Review' Annual. Beverly Hills, CA: Sage.

College van Burgemeester en Wethouders (1990) 'Sociale vernieuwing Rotterdam: Inzet van de gemeente', Social Renewal Rotterdam: Objectives of the Municipality. Rotterdam.

College van Burgemeester en Wethouders (1994) De inzet gevolgd. Eindrapportage project Sociale vernieuwing (Following the start, Final report on social revitalization), Rotterdam.

Fine, M. (1994) 'Working the Hyphens: Reinventing Self and Other in Qualitative Research', in N. K. Denzin and Y. S. Lincoln (eds) Handbook of Qualitative Research, pp. 70-82. Thousand Oaks, CA: Sage.

Fischer, F. (1980) Politics, Values and Public Policy: The Problem of Methodology. Boulder, $\mathrm{CO}$.

Fischer, F. (1990) Technocracy and the Politics of Expertise. Newbury Park, CA: Sage.

Fischer, F. and J. Forester, eds (1987) Confronting Values in Policy Analysis. The Politics of Criteria, Sage Yearbooks in Politics and Public Policy, 14. Newbury Park, CA: Sage.

Flax, J. (1993) Disputed Subjects-Essays on Psychoanalysis, Politics and Philosophy. New York and London: Routledge.

Fortuin, K. (1991) Berichten uit de samenleving 1, eerste deelrapportage (Messages from society 1 , first report), Nederlands instituut voor onderzoek naar maatschappelijke opbouw in opdracht van projectbureau sociale vernieuwing Rotterdams'-Hertogenbosch.

Fortuin, K. (1994a) Berichten uit de samenleving, Syntheserapport (Messages from society, Synthesis). Utrecht: Verwey-Jonker Instituut.

Fortuin, K. (1994b) 'Evaluatie in een paradoxale beleidscontext' (Evaluation in a paradoxical policy context), in A. Francke and R. Richardson (eds) Kwalitatief evaluatie-onderzoek. Coutingho.

Fortuin, K. and R. Hovingh (1992) Berichten uit de samenleving 2, tweede deelrapportage (Messages from society 2, second report). Nederlands instituut voor onderzoek naar maatschappelijke opbouw in opdracht van projectbureau sociale vernieuwing Rotterdam, Rotterdam. 
Frissen, P. H. A. (1996) De virtuele staat, Politiek, bestuur, technologie: een postmodern verhaal (The virtual state, politics, administration and technology: A postmodern tale), Academic service.

Greene, Jennifer C. (1987) 'Stakeholder Participation in Evaluation Design. Is it Worth the Effort?', Evaluation and Program Planning 10: 379-94.

Guba, E. G. and Y. S. Lincoln (1981) Effective Evaluation, Improving the Usefulness of Evaluation Results Through Responsive and Naturalistic Approaches. San Francisco: Jossey-Bass.

Guba, E. G. and Y. S. Lincoln (1989) Fourth Generation Ev'aluation. Beverly Hills, CA: Sage.

Harvey, D. (1989) The Condition of Postmodernity: An Enquiry into the Origins of Cultural Change. Oxford: Blackwell.

Heshusius, L. (1994) 'Freeing Ourselves from Objectivity, Managing Subjectivity or Turning Toward a Participatory Mode of Consciousness?', Educational Researcher, April: 15-22.

House, E. R. (1980) Evaluating with Validity. Beverly Hills, CA: Sage.

House, E. R. (1991) 'Evaluation and Social Justice, Where are We?', in M. W. McLaughlin and D. C. Philips (eds) Evaluation and Education, Ninetieth Yearbook of the National Society for the Study of Education, Part 11, pp. 232-47. Chicago, IL: University of Chicago Press.

Idenburg, P. (1989) Commissie sociale vernieuwing, Het nieuwe Rotterdam in sociaal perspectief (The New Rotterdam in a social perspective).

In't Veld, R. (1995) Spelen met vuur, over hybride organisaties (Playing with fire, about hybrid organizations). 's-Gravenhage: VUGA.

Jameson, F. (1991) Postmodernism, or, the Cultural Logic of Late Capitalism. Durham, NC: Duke University Press.

Kaplan, T. J. (1986) 'The Narrative Structure of Policy Analysis', Journal of Policy Analysis and Management 5: 761-78.

Kensen, S. (1993) 'Postmodern Organizing in the Dutch Public Sector in the Eighties and Nineties', paper presented at the 11 th European Group for Organizational Studies (EGOS) Colloquium The Production and Diffusion of Managerial and Organizational Knowledge, Paris, 6-8 July.

Lincoln, Y. S. (1993) 'I and Thou: Method, Voice and Roles in Research with the Silenced', in D. McLaughlin and W. Tierney (eds) Naming Silenced Lives, pp. 29-47. London: Routledge.

Lincoln, Y. S. and E. G. Guba (1985) Naturalistic Inquiry. Thousand Oaks, CA: Sage.

MacRae, D. (1976) The Social Function of Social Science. New Haven, CT: Yale University Press.

Marcus, G. E. (1994) 'What Comes (just) after 'Post'? The Case of Ethnography', in N. K. Denzin and Y. S. Lincoln (eds) Handbook of Qualitative Research, pp. 563-74. London: Sage.

Nussbaum, M. C. (1990) Love's Knowledge, Essays on Philosophy and Literature. New York, Oxford: Oxford University Press.

Osborne, D. E. and T. Gaebler (1992) Reinienting Government: How the Entreprenurial Spirit is Transforming the Public Sector. New York: Plume.

Patton, M. Q. (1986) Utilization-Focused Evaluation. 2nd edn. Beverly Hills, CA: Sage.

Patton, M. Q. (1988) 'The Evaluator's Responsibility for Utilization', Evaluation Practice 9(2): 5-24.

Polanyi, M. (1966) The Tacit Dimension. New York: Doubleday.

Rein, M. (1976) Social Science and Public Policy. Harmondsworth: Penguin Education.

Rorty, R. (1979) Philosophy and the Mirror of Nature. Princeton, NJ: Princeton University Press.

Rorty, R. (1989) Contingency, Irony and Solidarity. Cambridge: Cambridge University Press. 
Tineke A. Abma

Rossi, P. H. and H. E. Freeman (1985) Evaluation: A Systematic Approach, 3rd edn. Beverly Hills. CA: Sage.

Schwandt, T. A. (1994) 'Constructivist, Interpretivist Approaches to Human Inquiry', in N. K. Denzin and Y. S. Lincoln (eds) Handbook of Qualitative Research, pp. 118-37. London: Sage.

Stake, R. E. (1975) 'To Evaluate an Arts Program', in R. E. Stake (ed.) Evaluating the Arts in Education: A Responsive Approach, pp. 89-102. Columbus, OH: Merrill.

Stake, R. E. (1991) 'Retrospective on the Countenances of Educational Evaluation', in M. W. McLaughlin and D. C. Philips (eds) Evaluation and Education. Ninetieth Yearbook of the National Society for the Study of Education, Part 11. Chicago, IL: University of Chicago Press.

Stake, R. E. (1994) 'Case Studies', in N. Denzin and Y. S. Lincoln (eds) Handhook of Qualitative Research, pp. 236-47. London: Sage.

Stake R. E. and D. J. Trumbull (1982) 'Naturalistic Generalizations', Review' Journal of Philosophy and Social Science 7: 1-12.

Termeer, C. J. A. M. and M. J. W. van Twist (1991) 'Introduction to Configuration Approach: A Process Theory for Societal Steering', in R. J. in't Veld, L. Schaap, C. J. A. M. Termeer and M. J. W. van Twist (eds) Autopoeisis and Configuration Theory: New'Approaches to Societal Steering. pp. 19-30. Dordrecht: Kluwer.

Van Dongen, Henk (1991) 'Some Notions on Social Integration and Steering', in R. in't Veld, L. Schaap, C. J. A. M. Termeer, and M. J. W. van Twist (eds) Autopoiesis and Configuration Theory: New' Approaches to Societal Steering, pp. 47-54. Dordrecht: Kluwer.

Van Gunsteren, Herman R. (1992) Eigentijds burgerschap (Contemporary citizenship). 's-Gravenhage: WWR-publicatie, Sdu uitgeverij.

Van Twist, M. (1994) Verbale vernieuwing, aantekeningen over de kunst ran bestuurskunde (Verbal renewal, some notions of the art of public administration). 's-Gravenhage: VUGA.

Vanderplaat, M. (1995) 'Beyond Technique, Issues in Evaluating for Empowerment', Evaluation 1(1): $81-96$.

TINEKE A. ABMA is working at the Department of Health Policy and Management at the Erasmus University, Rotterdam, The Netherlands.

[email:abma@beno.bmg.eur.nl] 